\title{
RETRACTED ARTICLE: One-step synthesis of size-controlled CZTS quantum dots
}

\author{
Leena Arora • Vidya Nand Singh • G. Partheepan - T. D. Senguttuvan • \\ Kiran Jain
}

Received: 6 August 2014/Accepted: 19 January 2015/Published online: 13 February 2015

(C) The Author(s) 2015. This article is published with open access at Springerlink.com

This article has been retracted on the initiative of the corresponding author because significant portions were copied verbatim by the first author from an article that had already been published in Chemical Communications, 2011, 47, 11721-11723, doi:10.1039/C1CC14687D. Authors have admitted their mistake and apologized unreservedly to the authors of the above mentioned manuscript, to Springer, and to the readers of Applied
Nanoscience. The online version of this article contains the full text of the retracted article as electronic supplementary material.

Open Access This article is distributed under the terms of the Creative Commons Attribution License which permits any use, distribution, and reproduction in any medium, provided the original author(s) and the source are credited.

Electronic supplementary material The online version of this article (doi:10.1007/s13204-015-0404-z) contains supplementary material, which is available to authorized users.

L. Arora · V. N. Singh $(\bowtie) \cdot$ T. D. Senguttuvan $\cdot$ K. Jain CSIR-Network of Institutes for Solar Energy, Physics of Energy Harvesting Division, CSIR-National Physical Laboratory,

Dr. K. S. Krishnan Marg, New Delhi 110012, India

e-mail: vidyanands@yahoo.com; singhvn@nplindia.org

G. Partheepan

Department of Civil Engineering, MVGR College of

Engineering, Vizianagaram 535005, Andhra Pradesh, India 